\title{
Short residence duration was associated with asthma but not cognitive function in the elderly: USA NHANES, 2001-2002
}

\author{
Ivy Shiue ${ }^{1,2,3}$
}

Received: 1 November 2015 / Accepted: 5 October 2016/Published online: 18 October 2016

(C) The Author(s) 2016. This article is published with open access at Springerlink.com

\begin{abstract}
There has been a growing interest in how the built environment affects health and well-being. Housing characteristics are associated with human health while environmental chemicals could have mediated the effects. However, it is unclear if and how residence duration might have a role in health and well-being. Therefore, the aim of the present study was to investigate the associations among residence duration, common chronic diseases, and cognitive function in older adults in a national and population-based setting. Data were extracted from the US National Health and Nutrition Examination Survey, 2001-2002, with assessment information on demographics, lifestyle factors, housing characteristics, self-reported common chronic diseases, and cognitive function by using the digit symbol substitution test from the Wechsler Adult Intelligence Scale (a measurement of attention and psychomotor speed). Statistical analyses including the chi-square test, $t$ test, and survey-weighted general linear modeling and logistic regression modeling were performed. Residence duration was significantly associated with risk of asthma but not with other chronic disease, showing a longer stay in the same housing leading to lower risk of asthma (OR $0.43,95 \%$ CI $0.27-0.69, P=0.002$ ) among the American
\end{abstract}

Responsible editor: Philippe Garrigues

Ivy Shiue

ivy.shiue@northumbria.ac.uk

1 Faculty of Health and Life Sciences, Department of Healthcare, Northumbria University, Newcastle upon Tyne, England NE1 8ST, UK

2 Owens Institute for Behavioral Research, University of Georgia, Athens, USA

3 Alzheimer Scotland Dementia Research Centre, University of Edinburgh, Edinburgh, UK older adults. However, having asthma was not associated with cognitive function decline. In conclusion, residence duration was found to be associated with risk of asthma but not cognitive function. Future research examining the relationship of residence duration and cognitive tests by other domains of cognitive function following asthma episodes would be suggested. For practice and policy implications, familiarity with the housing environment might help with lessening respiratory symptoms.

Keywords Housing $\cdot$ Cognitive function $\cdot$ Risk factor . Aging $\cdot$ Chronic disease $\cdot$ Asthma

\section{Introduction}

\section{Evidence before this study}

There has been a growing interest in how the built environment, including our own homes, affects our health and wellbeing in recent years (Mitty 2010). Early animal studies observed that the defeated and subsequently individually housed rats displayed impaired social memory, decreased social interaction, and diminished anticipation for a sucrose solution for up to a period of 3 months (Von Frijtag et al. 2000), and cognitive deficits were followed by an interaction of genotype and housing environment in rodent models of schizophrenia (Turner and Burne 2013) or Alzheimer's disease (Pietropaolo et al. 2014; Ambrée et al. 2006) to affect learning and memory functioning (Marques et al. 2009; Sonninen et al. 2006). In human studies, housing instability in the 12 months prior to baseline was found to predict lower verbal cognitive abilities across all age groups (Fowler et al. 2015), likely through the mechanisms of reward ("optimism") or punishment ("pessimism") systems (Parker et al. 2014), parental disruption (Coley et al. 2013), or 


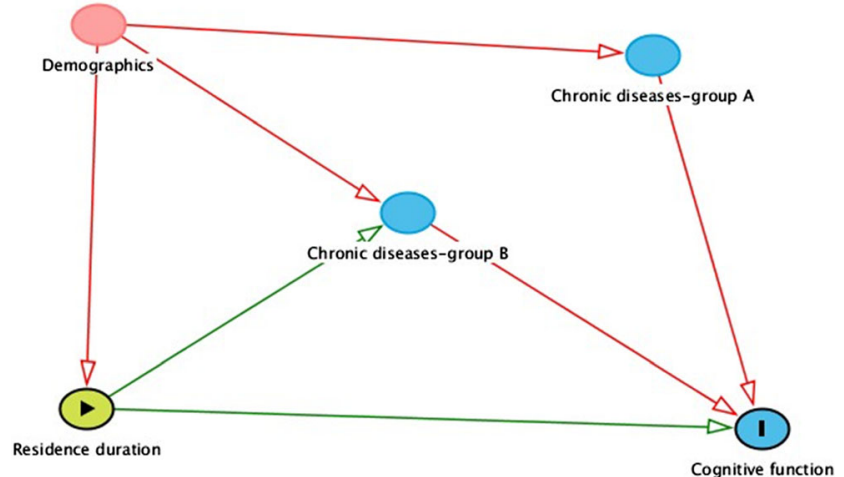

Fig. 1 Pathway of residence duration, chronic disease, and cognition

relocation controllability and adjustment (Bekhet and Zauszniewski 2013). Some of the relocated nursing home residents also demonstrated significant higher levels of salivary cortisol and lower depression, anxiety, and pulse rates than those who had not yet moved (Hodgson et al. 2004). However, this might depend on extensive relocation preparation and support to diminish the stress of relocation over time and across diagnostic categories (Lander et al. 1997; Engle 1985).

\section{Knowledge gap}

Housing inequalities could pose significant social and health problems in many societies. Several studies have investigated the effects of housing characteristics on adult human health and biomarkers (Jacobs et al. 2009; Shiue and Shiue 2003), with more literature focusing on children. Even environmental chemicals could have a role in mediating the housing effect on adult health conditions (Shiue and Bramley 2015). However, there has been limited consideration of the potential effect of residence duration, a probabilistic risk assessment method in establishing the distribution of exposure in a population (Sedman et al. 1998), on human health including chronic diseases and cognitive function.

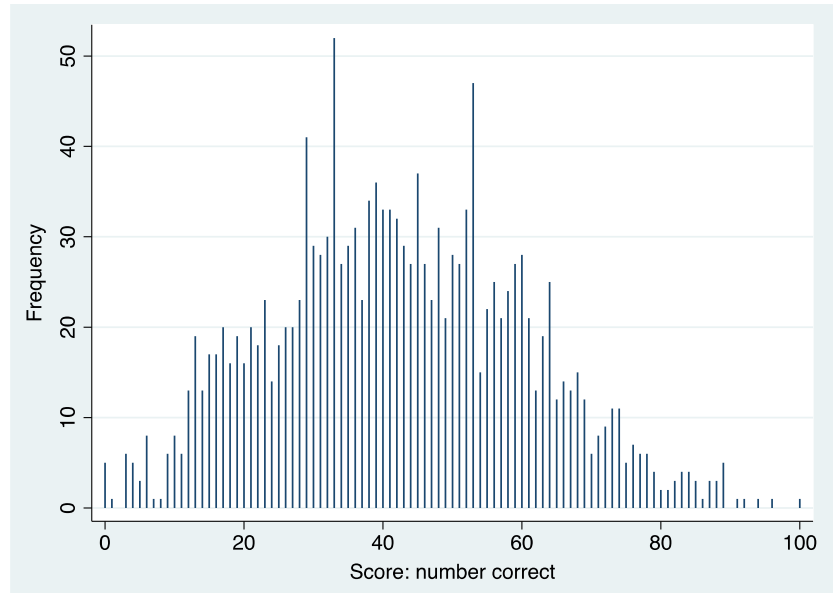

Fig. 2 Distribution of digit symbol score with correct answers in the elderly aged $60+$

\section{Study aim}

Following this context, therefore, the aim of the present study was to investigate the associations among residence duration, common chronic diseases and cognitive function (see the illustrated pathway in Fig. 1) in older adults in a national and population-based setting.

\section{Method}

\section{Study sample and variables}

The US National Health and Nutrition Examination Survey (NHANES) has been a national, population-based, multi-year, cross-sectional study representative of the entire American population. For the current analysis, data from the 2001 and 2002 (more details on the sampling method and procedure via http://wwwn.cdc.gov/nchs/nhanes/search/datapage. aspx ?Component $=$ Questionnaire $\&$ CycleBegin Year $=2001$ ) that were with cognitive function assessment were retrieved. In other words, there was no cognitive function measured after 2002, so no recent data could be used for analysis. Moreover, only older adults aged 60 and above were included in the present study because the cognitive function was measured in this age group only.

Information on demographics (more details via http://wwwn. cdc.gov/nchs/nhanes/search/datapage.aspx?Component= Demographics\&CycleBegin Year=2001), residence duration (question: How many years have you lived at this address? more details via http://wwwn.cdc.gov/nchs/nhanes/2001-2002/HOQ_B. $\mathrm{htm}$ ), self-reported chronic diseases (question: Has a doctor or other health professionals ever told you that you have $\mathrm{X}$ disease? more details via http://wwwn.cdc.gov/nchs/nhanes/2001-2002 /MCQ_B.htm) and cognitive function (the digit symbol substitution test from the Wechsler Adult Intelligence Scale, a

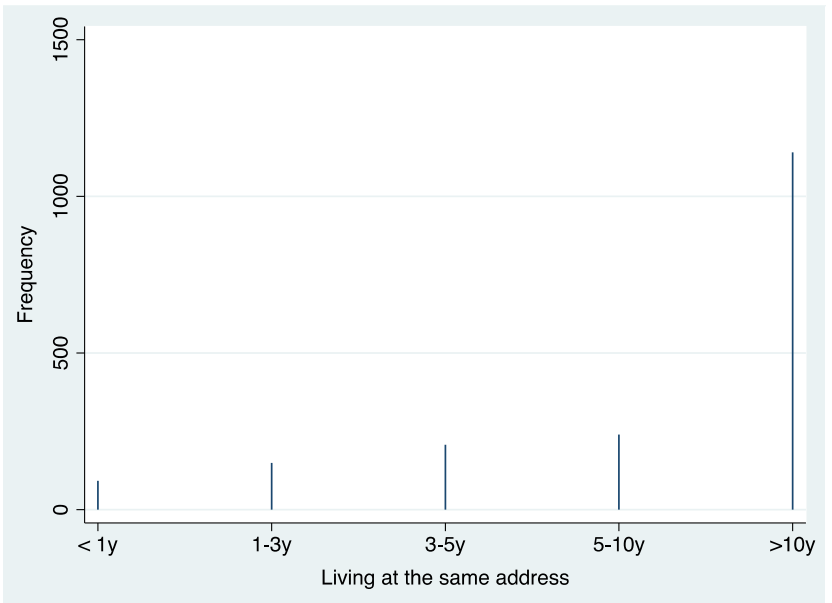

Fig. 3 Distribution of housing residing duration in the elderly aged $60+$ 
Table 1 Associations of chronic diseases and digit symbol score $(n=1558)$

\begin{tabular}{lrllr}
\hline Prior health events & & $\begin{array}{l}\text { Present } \\
\text { Mean (SD) }\end{array}$ & $\begin{array}{l}\text { Absent } \\
\text { Mean (SD) }\end{array}$ & $P$ value \\
\hline Asthma & $124 / 1557$ & $41.7(18.8)$ & $42.2(18.2)$ & 0.769 \\
Arthritis & $723 / 1556$ & $41.6(18.1)$ & $42.7(18.3)$ & 0.230 \\
Stroke & $105 / 1552$ & $31.1(15.8)$ & $43.0(18.1)$ & $<0.001$ \\
Heart attack & $165 / 1550$ & $35.0(14.3)$ & $42.8(18.3)$ & $<0.001$ \\
Emphysema & $61 / 1554$ & $38.5(15.5)$ & $42.3(18.3)$ & 0.107 \\
Heart failure & $105 / 1543$ & $38.1(17.3)$ & $42.7(18.3)$ & 0.002 \\
Coronary heart disease & $158 / 1535$ & $42.8(16.6)$ & $42.3(18.4)$ & 0.746 \\
Angina & $118 / 1538$ & $39.8(15.2)$ & $42.5(18.4)$ & 0.118 \\
Chronic bronchitis & $97 / 1555$ & $41.0(15.6)$ & $42.3(18.4)$ & 0.489 \\
Liver problem & $49 / 1553$ & $41.2(18.5)$ & $42.2(18.2)$ & 0.705 \\
Cancer & $322 / 1556$ & $43.8(17.4)$ & $41.8(18.4)$ & 0.089 \\
Diabetes & $265 / 1517$ & $37.1(16.8)$ & $43.2(18.4)$ & $<0.001$ \\
Blood transfusion & $351 / 1511$ & $41.8(16.4)$ & $42.2(18.8)$ & 0.702 \\
Trouble seeing & $358 / 1556$ & $36.3(17.4)$ & $43.9(18.1)$ & $<0.001$ \\
& & & &
\end{tabular}

measure of attention and psychomotor speed, DSS) was obtained by a household interview (The Psychological Corporation 1997; more details via http://wwwn.cdc.gov/nchs/nhanes/2001-2002 /CFQ_B.htm), which has been widely used and subsequently published (Shiue and Starr 2012).

\section{Statistical analysis}

In the first step of analysis, distribution of digit symbol scores and of residence duration was presented by using spike plots (see Figs. 2 and 3). In the second step of analysis, associations between common chronic diseases and cognitive function were examined by using the $t$ test. In the third step, associations between housing duration, common chronic disease, and digit symbol scores were examined by using the chi-square test and survey-weighted generalized linear models or logistic regression models depending on the study outcome being continuous or categorical. Effects were shown in odds ratios with $95 \%$ confidence intervals, with $P<0.05$ as statistically significant. Covariates including age, sex, education level, vitamin D level, cholesterol level, smoking habit, and physical activity level were adjusted in the statistical models. STATA statistical software version 13.0 (STATA, College Station, Texas, USA; more details via http://www.stata.com/) was used to perform all the statistical analyses.

\section{Ethics considerations}

Since there were only secondary data analyses employed without any participant's personal information identified by extracting statistical data from the UK Data Archive website in the present study, no further ethics approval for conducting the present study was required (more details via http://www. ethicsguidebook.ac.uk/Secondary-analysis-106).

\section{Results}

Associations between common chronic diseases and cognitive function are shown in Table 1. Apparently, people with previous stroke, heart attack, heart failure, diabetes, or trouble
Table 2 Associations of residence duration, chronic diseases, and digit symbol score $(n=1558)$

\begin{tabular}{llllll}
\hline & $\begin{array}{l}<10 \mathrm{years} \\
(n=688,37.6 \%)\end{array}$ & $\begin{array}{l}>10 \mathrm{y}(n=1140, \\
62.4 \%)\end{array}$ & $P$ value & OR $(95 \% \mathrm{CI})^{*}$ & $P$ value \\
\hline Digit symbol score & $41.2(18.4)$ & $43.0(18.1)$ & 0.067 & - & - \\
Asthma & $76 / 687$ & $77 / 1140$ & 0.001 & $0.43(0.27-0.69)$ & 0.002 \\
Arthritis & $302 / 688$ & $552 / 1137$ & 0.054 & $1.13(0.79-1.61)$ & 0.478 \\
Stroke & $62 / 685$ & $97 / 1136$ & 0.708 & $1.00(0.56-1.79)$ & 0.994 \\
Heart attack & $78 / 684$ & $124 / 1134$ & 0.758 & $0.91(0.53-1.56)$ & 0.720 \\
Emphysema & $37 / 683$ & $37 / 1138$ & 0.023 & $0.50(0.23-1.07)$ & 0.072 \\
Heart failure & $62 / 683$ & $79 / 1126$ & 0.113 & $0.97(0.57-1.66)$ & 0.898 \\
Coronary heart disease & $70 / 677$ & $113 / 1117$ & 0.880 & $0.94(0.63-1.42)$ & 0.765 \\
Angina & $57 / 677$ & $85 / 1127$ & 0.503 & $1.03(0.52-2.05)$ & 0.921 \\
Chronic bronchitis & $47 / 685$ & $74 / 1138$ & 0.766 & $0.99(0.51-1.90)$ & 0.969 \\
Liver problem & $24 / 684$ & $30 / 1137$ & 0.289 & $0.79(0.28-2.20)$ & 0.634 \\
Cancer & $127 / 685$ & $255 / 1140$ & 0.052 & $1.36(0.99-1.88)$ & 0.057 \\
Diabetes & $129 / 674$ & $194 / 1108$ & 0.386 & $0.91(0.59-1.38)$ & 0.624 \\
Blood transfusion & $174 / 670$ & $284 / 1103$ & 0.917 & $0.99(0.75-1.31)$ & 0.944 \\
Trouble seeing & $205 / 688$ & $276 / 1138$ & 0.009 & $0.73(0.50-1.06)$ & 0.091 \\
\hline
\end{tabular}

*Adjusted for age, sex, education level, vitamin D level, cholesterol level, smoking habit, physical activity level, and survey weighting 
seeing had lower digit symbol scores. Residence duration was significantly associated with risk of asthma but not with other chronic diseases (see Table 2), showing a longer stay in the same housing leading to lower risk of asthma (OR 0.43, 95\%CI 0.27-0.69, $P=0.002$ ) among the American older adults. However, having asthma was not associated with cognitive function decline.

\section{Discussion}

\section{Housing, chronic diseases, and cognition}

The linkage of vascular risk factors (including stroke, heart attack, and diabetes) and late-life cognitive decline has been well established (Tuligenga 2015; Carmichael 2014; Knopman et al. 2009) while that of heart failure and cognitive function has been unconfirmed (Cannon et al. 2015). Plausible underlying mechanisms might be related to cerebral hypoperfusion or occult cerebrovascular disease, and it seems likely that these may coexist and exert synergistic effects. Moreover, there is no specific treatment guidance in this (Cannon et al. 2015; Carmichael 2014). Recently, it was also observed that people with vision loss due to three different age-related eye diseases could have lower cognitive scores (Harrabi et al. 2015). The findings from the present study are consistent with those in the abovementioned literature.

The risk of asthma was related to the length of stay in older adults as observed in the present study, although from previous research, the effect seemed to be the opposite in children (Cabieses et al. 2014). Similarly, in previous animal studies, it was also observed that there was an inverse association between residence duration and cognitive impairment in polar environments (John Paul et al. 2010; Reed et al. 2001) or the dependent context (Missotten et al. 2009; Jackson 1974). One of the reasons in such contrast between the literature and the present study might be that older adults could have been better accustomed to the living environment for a longer period of time living in the same or similar environment.

\section{Strengths and limitations}

The present study has a few strengths. Firstly, this exploratory study is the first to examine the associations among residence duration, common chronic disease, and cognitive function in the elderly aged 60 and above from the general population in a national setting. Secondly, many different types of common chronic diseases were able to be included. However, there are also limitations that cannot be ignored. First, cognitive function was only assessed by the digit symbol test while there are other tests to measure different domains of cognition along the life course. Second, only associations but not the causality can be established in the present study due to the cross- sectional observational study design in nature. Taken together, future research with a longitudinal approach plus other cognitive tests measuring other domains of cognitive function to confirm or refute the current observation would be warranted.

\section{Directions for future research, practice, and policy}

In conclusion, residence duration was found to be associated with risk of asthma but not cognitive function. Future research examining the relationship of residence duration and cognitive tests by other domains of cognitive function following asthma episodes would be suggested. For practice and policy implications, familiarity with the housing environment might help with lessening respiratory symptoms.

Compliance with ethical standards Since there were only secondary data analyses employed without any participant's personal information identified by extracting statistical data from the UK Data Archive website in the present study, no further ethics approval for conducting the present study was required (more details via http://www.ethicsguidebook.ac. uk/Secondary-analysis-106).

Conflict of interest The authors declare that they have no conflict of interest.

Open Access This article is distributed under the terms of the Creative Commons Attribution 4.0 International License (http:// creativecommons.org/licenses/by/4.0/), which permits unrestricted use, distribution, and reproduction in any medium, provided you give appropriate credit to the original author(s) and the source, provide a link to the Creative Commons license, and indicate if changes were made.

\section{References}

Ambrée O, Leimer U, Herring A, Görtz N, Sachser N, Heneka MT, Paulus W, Keyvani K (2006) Reduction of amyloid angiopathy and Abeta plaque burden after enriched housing in TgCRND8 mice: involvement of multiple pathways. Am J Pathol 169(2):544-552

Bekhet AK, Zauszniewski JA (2013) Resourcefulness, positive cognitions, relocation controllability and relocation adjustment among older people: a cross-sectional study of cultural differences. Int J Older People Nursing 8(3):244-252

Cabieses B, Uphoff E, Pinart M, Antó JM, Wright J (2014) A systematic review on the development of asthma and allergic diseases in relation to international immigration: the leading role of the environment confirmed. PLoS One 9:e105347

Cannon JA, McMurray JJ, Quinn TJ (2015) 'Hearts and minds': association, causation and implication of cognitive impairment in heart failure. Alzheimers Res Ther 7:22

Carmichael O (2014) Preventing vascular effects on brain injury and cognition late in life: knowns and unknowns. Neuropsychol Rev 24:371-387

Coley RL, Leventhal T, Lynch AD, Kull M (2013) Relations between housing characteristics and the well-being of low-income children and adolescents. Dev Psychol 49(9):1775-1789

Engle VF (1985) Mental status and functional health 4 days following relocation to a nursing home. Res Nurs Health 8(4):355-361

Fowler PJ, McGrath LM, Henry DB, Schoeny M, Chavira D, Taylor JJ, Day O (2015) Housing mobility and cognitive development: change 
in verbal and nonverbal abilities. Child Abuse Negl 13(15):0022200227. doi:10.1016/j.chiabu.2015.06.002

Harrabi H, Kergoat MJ, Rousseau J, Boisjoly H, Schmaltz H, Moghadaszadeh S, Roy-Gagnon MH, Freeman EE (2015) Agerelated eye disease and cognitive function. Invest Ophthalmol Vis Sci 56:1217-1221

Hodgson N, Freedman VA, Granger DA, Erno A (2004) Biobehavioral correlates of relocation in the frail elderly: salivary cortisol, affect, and cognitive function. J Am Geriatr Soc 52(11):1856-1862

Jackson DW (1974) Relationship of residence, education, and socialization to cognitjye tasks in normal people of advanced old age. Psychol Rep 35:423-426

Jacobs DE, Wilson J, Dixon SL, Smith J, Evens A (2009) The relationship of housing and population health: a 30-year retrospective analysis. Environ Health Perspect 117:597-604

John Paul FU, Mandal MK, Ramachandran K, Panwar MR (2010) Cognitive performance during long-term residence in a polar environment. J Environ Psy 30:129-132

Knopman DS, Roberts RO, Geda YE, Boeve BF, Pankratz VS, Cha RH, Tangalos EG, Ivnik RJ, Petersen RC (2009) Association of prior stroke with cognitive function and cognitive impairment: a population-based study. Arch Neurol 66:614-619

Lander SM, Brazill AL, Ladrigan PM (1997) Intrainstitutional relocation. Effects on residents' behavior and psychosocial functioning. J Gerontol Nurs 23(4):35-41

Marques JM, Alonso I, Santos C, Silveira I, Olsson IA (2009) The spatial learning phenotype of heterozygous leaner mice is robust to systematic variation of the housing environment. Comp Med 59(2):129-138

Missotten P, Thomas P, Squelard G, Di Notte D, Fontaine O, Paquay L, De Lepeleire J, Buntinx F, Ylieff M (2009) Impact of place of residence on relationship between quality of life and cognitive decline in dementia. Alzheimer Dis Assoc Disord 23:395-400

Mitty E (2010) An assisted living community environment that optimizes function: housing enabler assessment. Geriatr Nurs 31(6):448-451

Parker RM, Paul ES, Burman OH, Browne WJ, Mendl M (2014) Housing conditions affect rat responses to two types of ambiguity in a reward-reward discrimination cognitive bias task. Behav Brain Res 274:73-83

Pietropaolo S, Feldon J, Yee BK (2014) Environmental enrichment eliminates the anxiety phenotypes in a triple transgenic mouse model of Alzheimer's disease. Cogn Affect Behav Neurosci. doi:10.3758 /s13415-014-0253-3

Reed HL, Reedy KR, Palinkas LA, Van Do N, Finney NS, Case HS, LeMar HJ, Wright J, Thomas J (2001) Impairment in cognitive and exercise performance during prolonged antarctic residence: effect of thyroxine supplementation in the polar triiodothyronine syndrome. J Clin Endocrinol Metab 86:110-116

Sedman R, Funk LM, Fountain R (1998) Distribution of residence duration in owner occupied housing. J Expo Anal Environ Epidemiol 8:51-58

Shiue I, Bramley G (2015) Environmental chemicals mediated the effect of old housing on adult health problems: US NHANES, 2009-2010. Environ Sci Pollut Res Int 22:1299-1308

Shiue I, Shiue YY. The role of housing characteristics in biomarkers: US NHANES, 2003 2006. Int J Cardiol. 2013; doi:10.1016/j. ijcard.2013.07.200.

Shiue I, Starr J (2012) Circulating urine phthalates are not associated with a decline in cognition in adults and the elderly: NHANES, 19992002. Neuroepidemiology 39(2):143-144

Sonninen R, Virtanen T, Sivenius J, Jolkkonen J (2006) Gene expression profiling in the hippocampus of rats subjected to focal cerebral ischemia and enriched environment housing. Restor Neurol Neurosci 24(1):17-23

Tuligenga RH. Intensive glycaemic control and cognitive decline in patients with type 2 diabetes: a meta-analysis. Endocr Connect. 2015.

Turner KM, Burne TH (2013) Interaction of genotype and environment: effect of strain and housing conditions on cognitive behavior in rodent models of schizophrenia. Front Behav Neurosci 7:97

Von Frijtag JC, Reijmers LG, Van der Harst JE, Leus IE, Van den Bos R, Spruijt BM (2000) Defeat followed by individual housing results in long-term impaired reward- and cognition-related behaviours in rats. Behav Brain Res 117(1-2):137-146

WAIS-III WMS-III Technical Manual. The Psychological Corporation, Harcourt Brace and Company. San Antonio:1997. 